Part of Journal of Research of the National Bureau of Standards, Volume 25, October 1940

\title{
METHOD FOR DETERMINING THE MOISTURE CONDITION IN HARDENED CONCRETE
}

\author{
By G. Rupert Gause and John Tucker, Jr.
}

\section{ABSTRACT}

A method for studying the moisture conditions inside hardened concrete and cement paste is described. An electric hygrometer developed by the National Bureau of Standards was used to measure the relative humidity in cavities at various locations in the material. The relative humidity inside 12 -inch concrete cubes stored at 50 percent relative humidity for 300 days was found to range from 50 percent near the surface to 66 percent near the center of the cube. For cubes stored at 20-percent relative humidity the corresponding range was from 20 to 60 percent. The relative humidity over cement paste of approximately normal consistency and cured in hermetically sealed bottles for 28 days was found to be 88 percent for a moderate heat-of-hardening cement and 79 percent for a highearly-strength cement.

I. Introduction

II. Description of hygrometer

III. Scope of tests

IV. Tests

1. Relative humidity within concrete exposed to drying ...... 407

2. Relative humidity inside hermetically sealed specimens_.... 413

$\begin{array}{ll}\text { (a) Effect of temperature } & 413 \\ \text { (b) Effect of setting and hardening of cement paste... } & 414\end{array}$

V. Accuracy of methodect of setting and hardening of cement paste....

method

VII. Summary and conclusions

\section{INTRODUCTION}

It has long been recognized that the moisture condition of concrete affects the volume changes, rate of hardening, and strength of concrete, as well as the life of coatings such as paint or linoleum, applied to the surface of the concrete. In laboratory tests changes in the moisture condition of concrete are usually obtained by weighing the specimen, any change in weight being assumed to be a loss or gain in water content. Since changes in the chemical or physical state of water in a concrete do not change the weight of the concrete, this method cannot measure changes in the moisture condition produced by hydration of the cement or by changes in the capillary structure of the concrete. On the other hand, carbonation at and near the surface of the concrete does change the weight without changing the water content, and this effect may be relatively large in the case of small specimens.

In the field, or where the moisture condition of concrete in situ is desired, the method lately developed by Spenser [1] ${ }^{1}$ is the only one

1 Figures in brackets indicate literature references at the end of this paper. 
giving quantitative results. This method consists in measuring the electrical conductance of the concrete and comparing it with the conductance of a sample of the same concrete cured without loss or gain of water. The results are expressed in terms of "percent available moisture lost", the total available moisture being defined by Spencer as the weight lost upon prolonged storage at 25-percent relative humidity and $70^{\circ} \mathrm{F}$. Spenser presents a calibration curve whereby the conductance measurements can be translated into "percent available moisture lost" units, thus eliminating the need for any weight measurements. This method, since it is a measure of weight changes, has the limitations of the laboratory weighing method and also several additional limitations which were pointed out by Spenser.

Davis [2] has shown that the shrinkage and expansion of concrete are closely related to the relative humidity of the air in which the concrete is stored. Jesser [3] has found that the vapor pressure of set cement decreases as the cement is dried and that the change is partly reversible. These relationships between the vapor pressure of set portland cement and both its water content and its volume changes are perhaps the strongest evidence upon which the colloidal theory of the setting and hardening of portland cement is based. Colloids lose water as the relative humidity of the surrounding air is decreased and reach a condition of equilibrium corresponding to each relative humidity. It is also well known that fine sands and soils may contain several percent of moisture while in equilibrium with air at a relative humidity of 90 percent, and the equilibrium relative humidity of soils has been suggested as a measure of their moisture content [4].

From the above it is apparent that the relative humidity inside concrete and cement pastes (i. e., in a cavity within the mass) may be of considerable importance. Since the relative humidity inside concrete must be the factor which determines whether a concrete will gain or lose water under any particular storage condition, it is reasonable to believe that the internal relative humidity will determine whether a concrete will shrink or expand under any particular storage condition, and also whether or not it is safe to apply paint or linoleum to the concrete surface. Furthermore, a measure of the relative humidity over cement pastes should give information concerning the physicochemical changes which take place during the setting and hardening of portland cement.

Spenser [1] recognized the importance of the relative humidity in concrete and attempted to measure it, but he was not successful because of the deterioration of the hair hygrometer used. Just before the present investigation was begun, F. W. Dunmore, of this Bureau, published his first report [5] dealing with the development of an electric hygrometer. It was therefore decided to investigate the possibilities of using this new hygrometer to measure the relative humidity inside concrete.

\section{DESCRIPTION OF HYGROMETER}

The development and construction of the electric hygrometer have been described in detail $[5,6]$. The instrument consists essentially of two separate wire helices wound on a small tube which is thinly coated with a hygroscopic material, see figure 1 . The electrical resistance between the two wires is a function of the relative humidity 
of the air surrounding the hygrometer. Calibration curves showing the relation between electrical resistance and relative humidity are given in figure 2 .

In the improved hygrometers described in reference [6], palladium wire is wound on polystyrene resin tubes. The hygroscopic coating is partially hydrolyzed polyvinyl acetate containing difierent percentages of lithium chloride, depending upon the humidity range for which the hygrometer is intended. This combination of materials produces a unit which is both very sensitive and very rapid in response. The rapid response of these electric hygrometers, as compared with the lagging response of hair hygrometers, is one of the factors which led to the adoption of the former for radio-sonde work.

The units developed for radio-sonde work were designed for a range of 10- to 90-percent relative humidity. Inside newly poured concrete the relative humidity is 100 percent, and considerable water may be lost before the relative humidity falls below 90 percent. Therefore, hygrometer units had to be constructed for this range. A satisfactory hygrometer was obtained by coating the unit with a very dilute polyvinyl acetate solution (containing no $\mathrm{LiCl}$ ) and by using polystyrene washers as binding posts, instead of the Bakelite washers, which were found to become conducting when stored at high humidities.

The hygrometer units were calibrated over saturated salt solutions producing known relative humidities. The salt solutions were kept in 8-ounce glass bottles taking No. 6 rubber stoppers. In order to calibrate a unit at a given humidity, it was placed in a bottle maintained at that relative humidity, the stopper

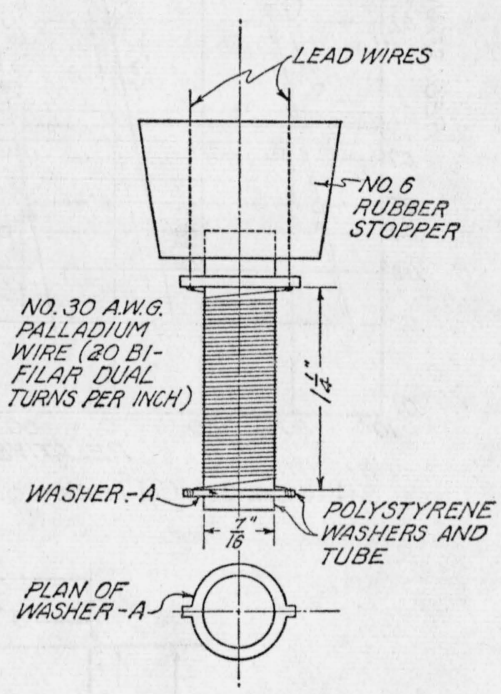

FIGURE 1.-Electric hygrometer. to which the unit was attached being used to close the bottle. Tables giving the relative humidity or vapor pressure produced by saturated solutions of various salts may be found in most handbooks and in the International Critical Tables.

The resistance of the units was measured with a Weston model 764 "capacity meter" calibrated to read in ohms.

\section{SCOPE OF TESTS}

The relative humidity at different depths (as indicated in fig. 3) inside 12-inch concrete cubes treated and stored as described in table 1 were observed over a period of 300 days. Similar observations were made in 6- by 12-inch concrete cylinders stored in tin molds with tops removed. The relative humidity inside hermetically sealed 6 - by $12-$ inch concrete cylinders was observed at temperatures varying from $60^{\circ}$ to $100^{\circ} \mathrm{F}$. The relative humidity over hermetically sealed neatcement pastes of approximately normal consistency was observed from the time of mixing until the pastes had aged 28 days. 


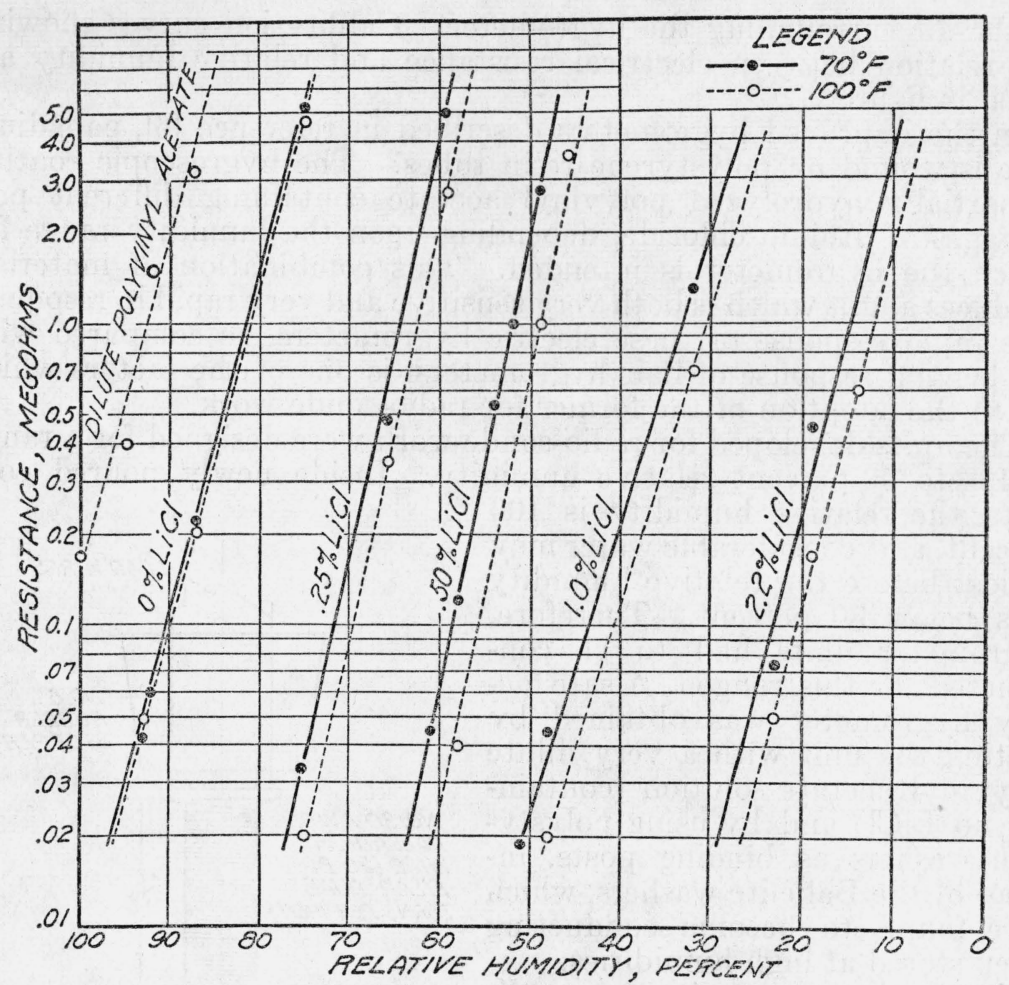

FIGURE 2.-Calibration curves for electric hygrometers.
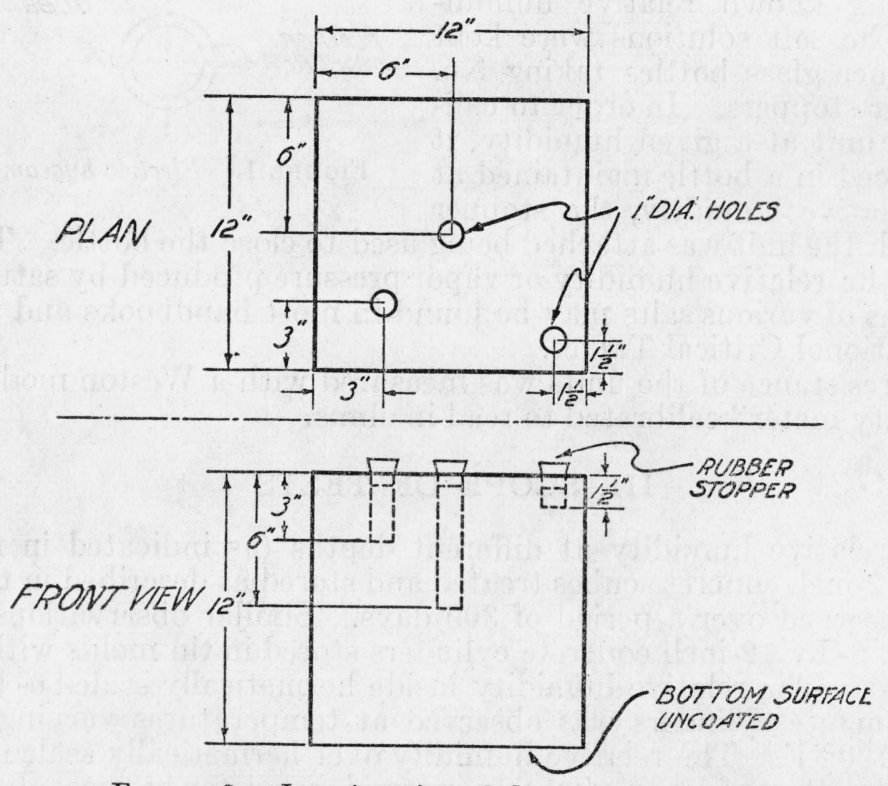

FigdRe 3.-Location of test holes in concrete cubes. 


\section{TESTS}

\section{RELATIVE HUMIDITY WITHIN CONCRETE EXPOSED TO DRYING}

Sixteen 12-inch concrete cubes were made, all from a 1:3:6 mix, $\mathrm{C} / \mathrm{W}$ by weight $=1.55$. Each specimen was cast with holes, as indicated in figure 3 . These holes were made by inserting 1 -inch steel rods into the concrete as soon as the form was filled and pulling out the rods after approximately 20 hours. After the rods were withdrawn, the holes were closed tightly with rubber stoppers. Eight of the cubes were stored for 28 days and the other eight for 4 days, in a damp-room. At the end of these storage periods four cubes of each set were coated on five sides, as indicated in table 1 , the uncoated side in each case being opposite the side containing the holes. The cubes were then placed in one of two drying rooms, one room being maintained at $100^{\circ} \pm 2^{\circ} \mathrm{F}$ and $50 \pm 10$-percent relative humidity, and the other room at $100^{\circ} \pm 1^{\circ} \mathrm{F}$ and $20 \pm 10$-percent relative humidity. By this scheme four pairs of cubes having the histories outlined in table 1 were stored in each of the two rooms.

TABLE 1.-History of 12-inch concrete cubes

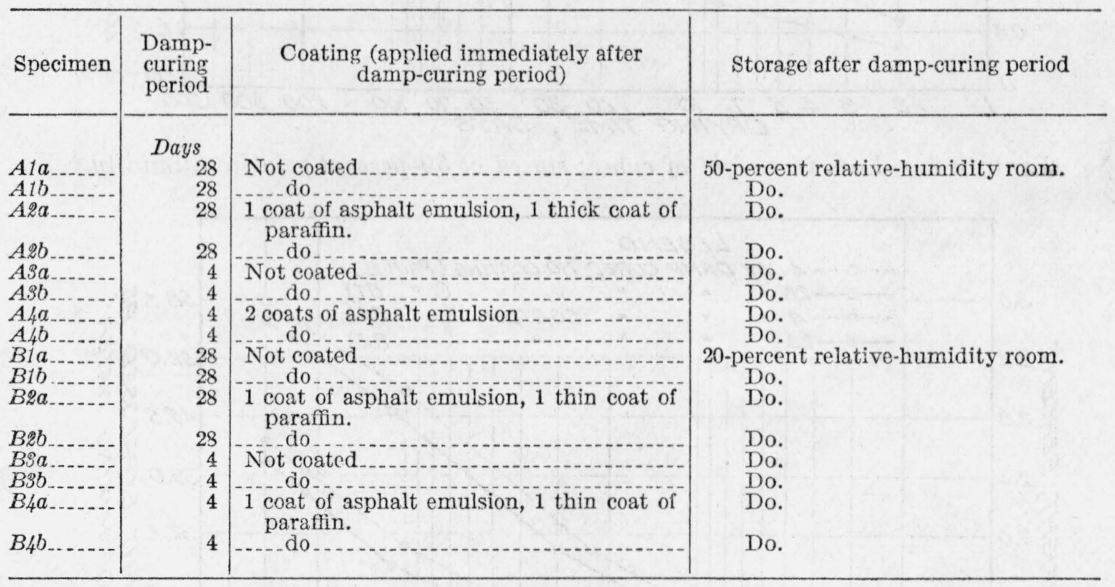

The thick paraffin coating on pair $A 2$ became soft at $100^{\circ} \mathrm{F}$, and this made the specimens very difficult to handle. Pair $A 4$ was therefore given two asphalt coatings and no paraffin coating. However, the asphalt coatings were not very effective and therefore pair $B 2$ and pair $B 4$ were given one coat of asphalt emulsion plus a thin coat of paraffin.

After the cubes were placed in the drying rooms, they were weighed and the relative humidity inside the holes measured at frequent intervals. In making humidity determinations, the stopper was removed from the hole in the concrete and a stopper with attached hygrometer unit placed as quickly as possible in the hole and forced in tightly. When, in this operation, the hole was left open for 5 minutes the humidity reading was at first low, but within 30 minutes was as high as before the hole was opened. The results obtained in these tests are given in figures 4 to 13 .

Figures 4 and 5 give the average loss in weight of each pair of cubes. 
There is an apparent anomaly in that the specimens stored at 50percent relative humidity, in some cases, lost more weight than the specimens stored at 20-percent relative humidity. However, pairs $A_{4}$ and $B_{4}$, in which this anomaly was most pronounced, were given

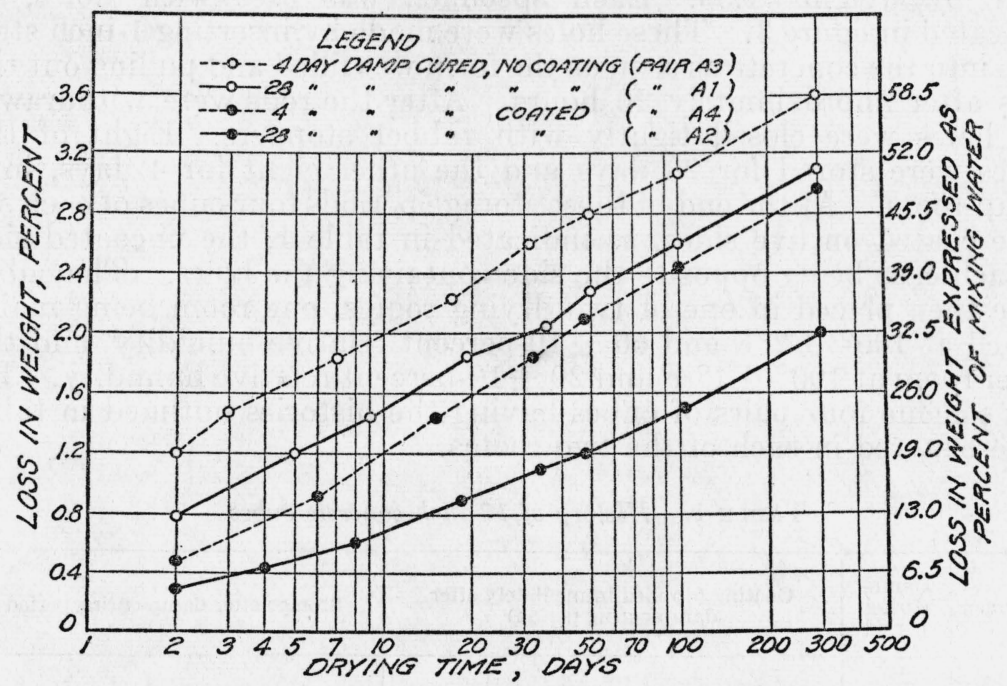

FIgURE 4.-Loss in weight of cubes; stored at 50-percent relative humidity.

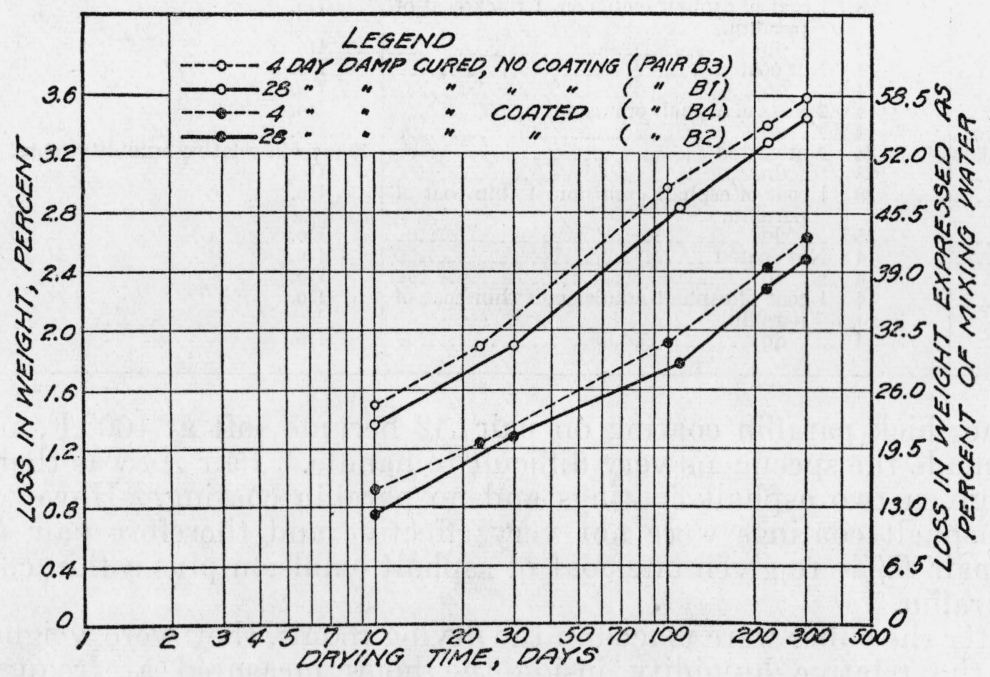

FIGURE 5.-Loss in weight of cubes; stored at 20-percent relative humidity.

different coatings. Furthermore, the 20-percent relative humidity room was much smaller than the 50-percent relative humidity room and, consequently, there may have been less circulation of air about the specimens in the former room. All specimens continued to lose weight throughout the entire 300 days of storage. However, in every case one-half the water lost in 300 days was lost the first 30 days. 
The relative humidities observed in the uncoated specimens are given in figures $6,7,8$, and 9 . These figures show that even after 300 days the relative humidity in the deeper holes is still fairly high but is continuing to decrease. Except for pairs $A_{2}$ and $A_{4}$, which

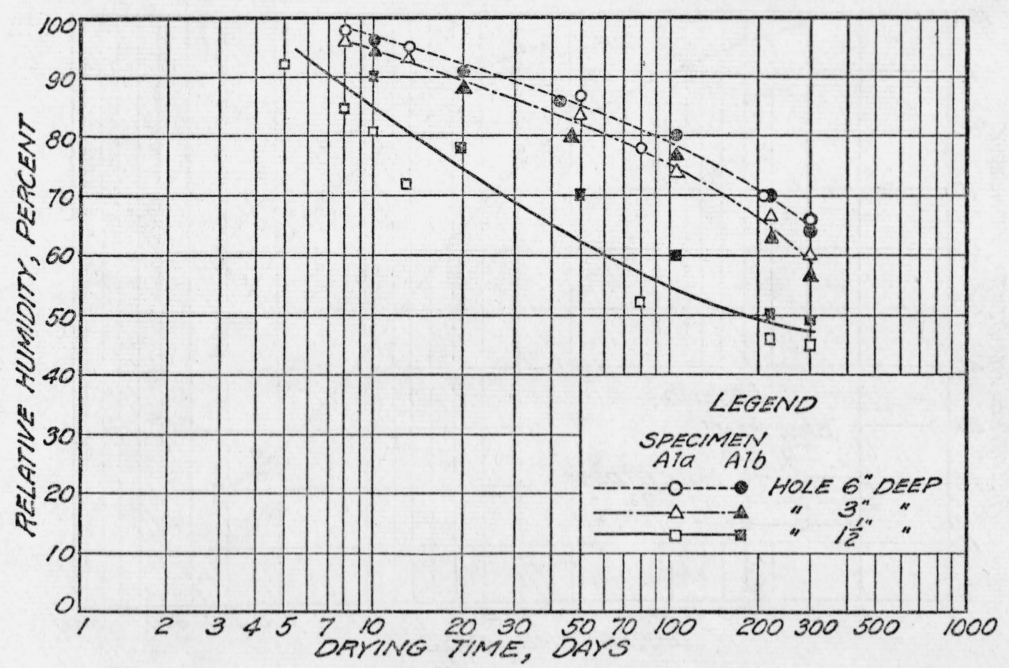

FIGURE 6.-Relative humidity in uncoated specimens damp-cured 28 days, then stored at 50-percent relative humidity, $100^{\circ} \mathrm{F}$ (pair A1).

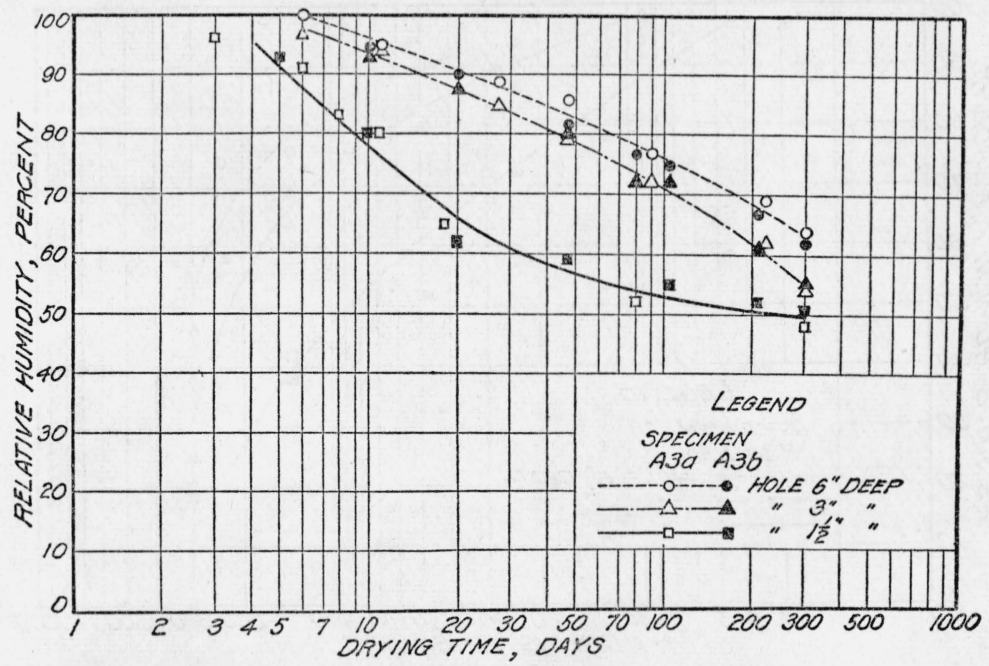

FIGURE 7.-Relative humidity in uncoated specimens damp-cured 4 days, then stored at 50-percent relative humidity, $100^{\circ} \mathrm{F}$ (pair AS).

have different types of coatings, there is no significant difference between the relative humidities in the four-day damp-cured specimens and those in the 28-day damp-cured specimens; however, figures 4 and 5 show that (except for pairs A2 and $A_{4}$ ) after 10 days' drying: time the weight lost by the 4-day damp-cured specimens exceeded 259104-40-2 
by a constant amount the weight lost by the 28-day damp-cured specimens. This indicates that the excess water lost by the 4-day damp-cured specimens during the first 10 days' drying time must have been water in excess of that required for producing 100-percent

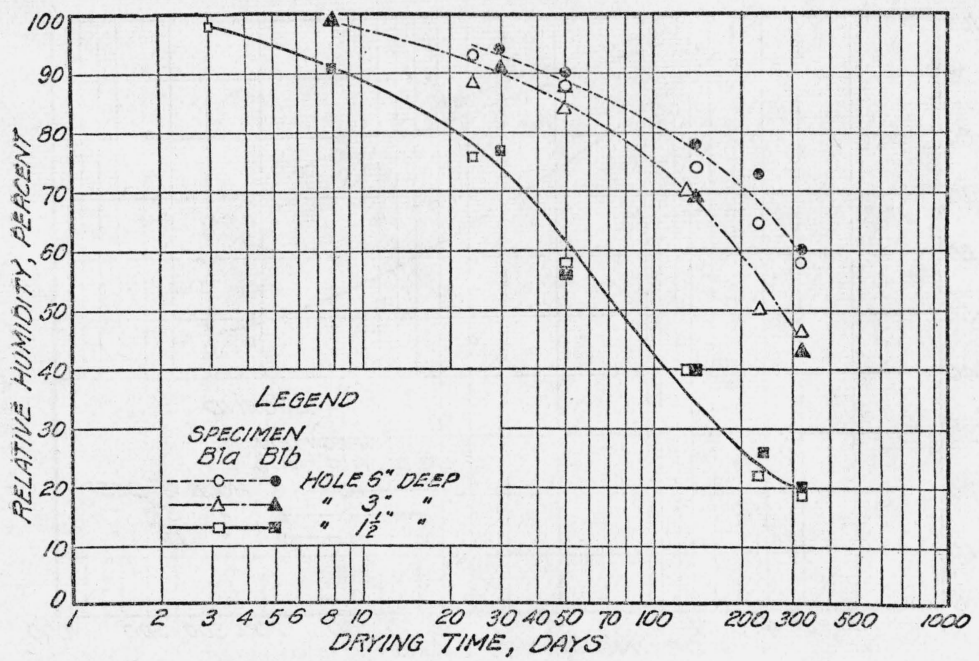

FIGURE 8.-Relative humidity in uncoated specimens damp-cured 28 days, then stored at 20-percent relative humidity, $100^{\circ} \mathrm{F}$ (pair B1).

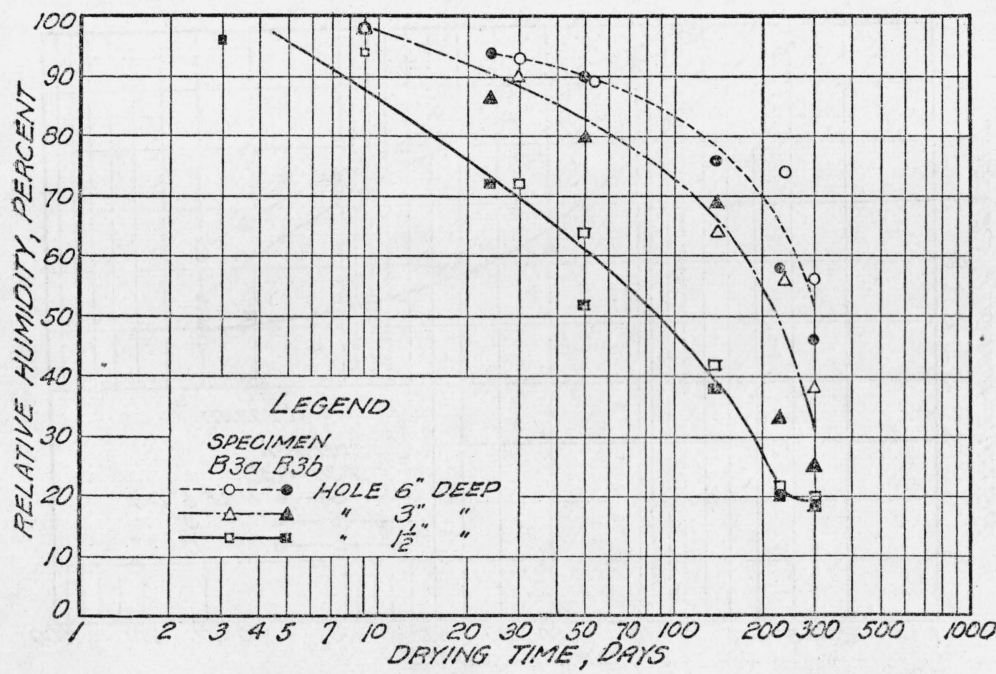

FIGURE 9.-Relative humidity in uncoated specimens damp-cured 4 days, then stored at 20-percent relative humidity, $100^{\circ} \mathrm{F}$ (pair B3).

relative humidity in the concrete. This excess water was lost very quickly in the drying room, after which the 4- and 28-day damp-cured specimens dried at equal rates.

The greatest difference between the humidity in specimens stored at 50-percent relative humidity and that in specimens stored at 20percent relative humidity is in the $1 \frac{1}{2}$-inch holes, where the humidity 
approached that of the storage room in each case. At any particular time the humidity in the deeper holes was about the same for the two conditions of storage. This emphasizes the fact that the interior of concrete dries very slowly, even under very dry storage conditions.

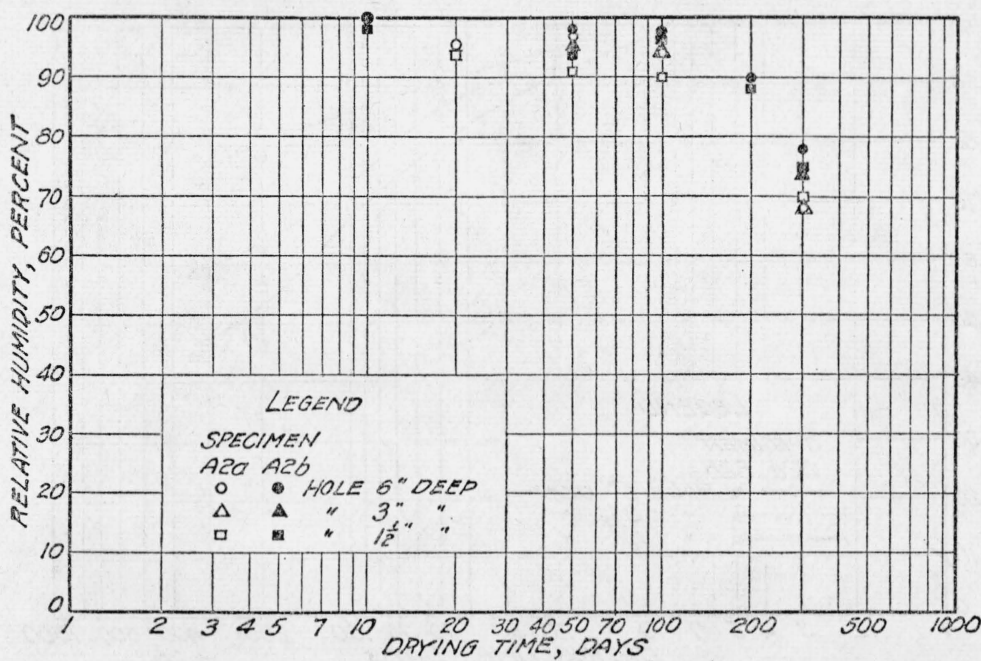

FIGURE 10.-Relative humidity in coated specimens damp-cured 28 days, then stored at 50-percent relative humidity, $100^{\circ} \mathrm{F}$ (pair A.).

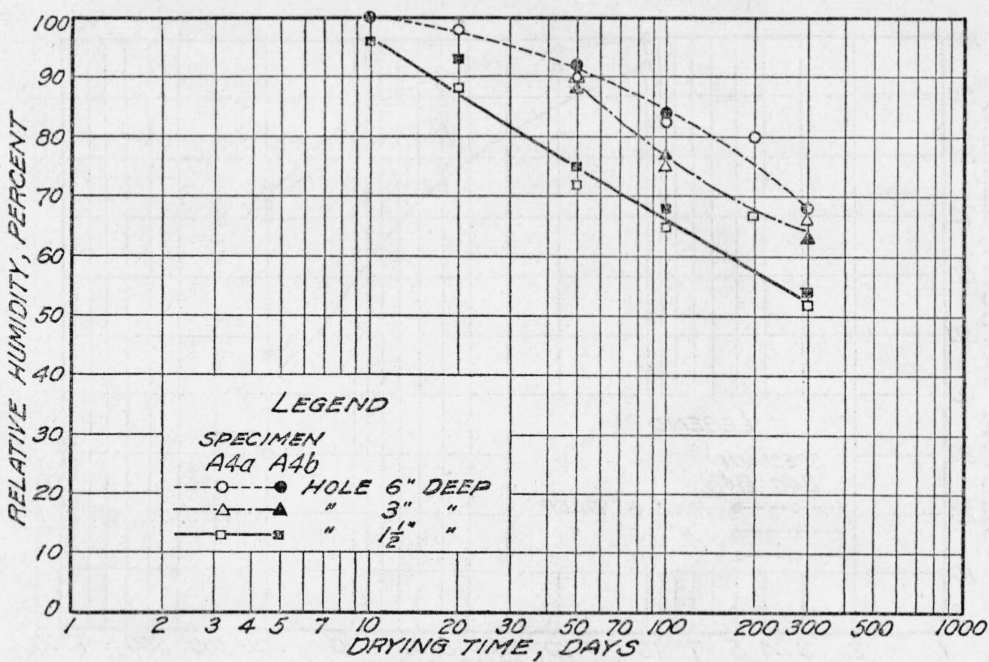

Figure 11.-Relative humidity in coated specimens damp-cured 4 days, then siored at 50-percent relative humidity, $100^{\circ} \mathrm{F}$ (pair A4).

Figures 10, 11, 12, and 13 give the relative humidities observed in the coated specimens. It is apparent from these figures that all of the coatings were somewhat pervious to water vapor, because, if all water lost had escaped from the uncoated side, then the 6-inch-deep holes, being nearest the uncoated side, should have been at a lower relative humidity than the 3 -inch-deep or $1 \frac{1}{2}$-inch-deep holes. In every pair, except $A 2$, the shallow holes became much drier than the deeper holes, 
and this was the pair with a very thick coat of paraffin. Small broken blisters were observed in the coatings of pairs $A 4, B 2$, and B4. Apparently the thick paraffin coating was the only coating which was very effective in preventing loss of water.

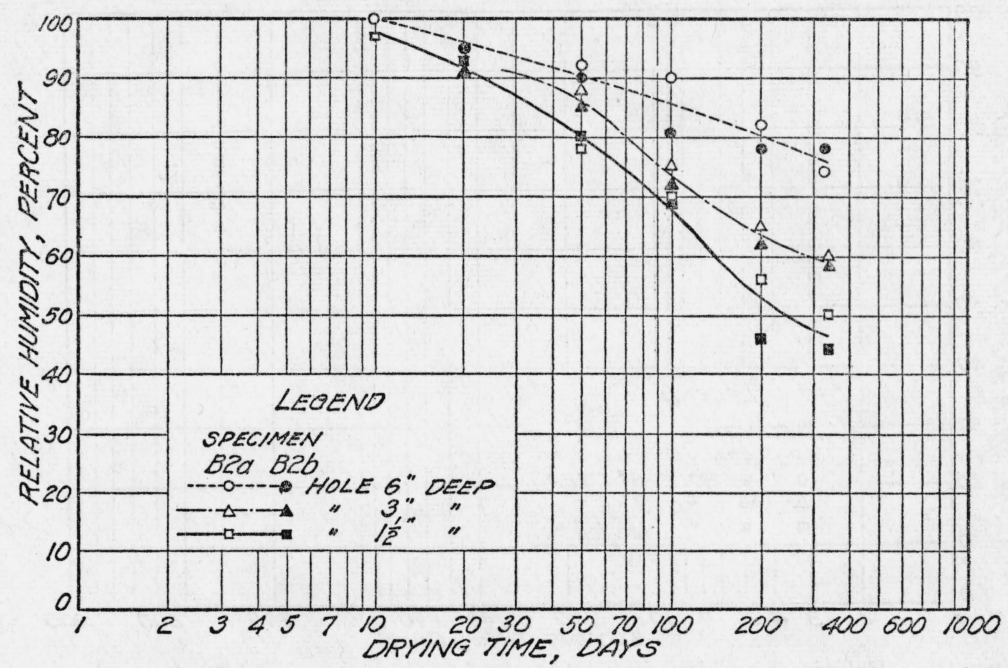

FIGURE 12.-Relative humidity in coated specimens damp-cured 28 days, then stored at 20-percent relative humidity, $100^{\circ} \mathrm{F}$ (pair B2).

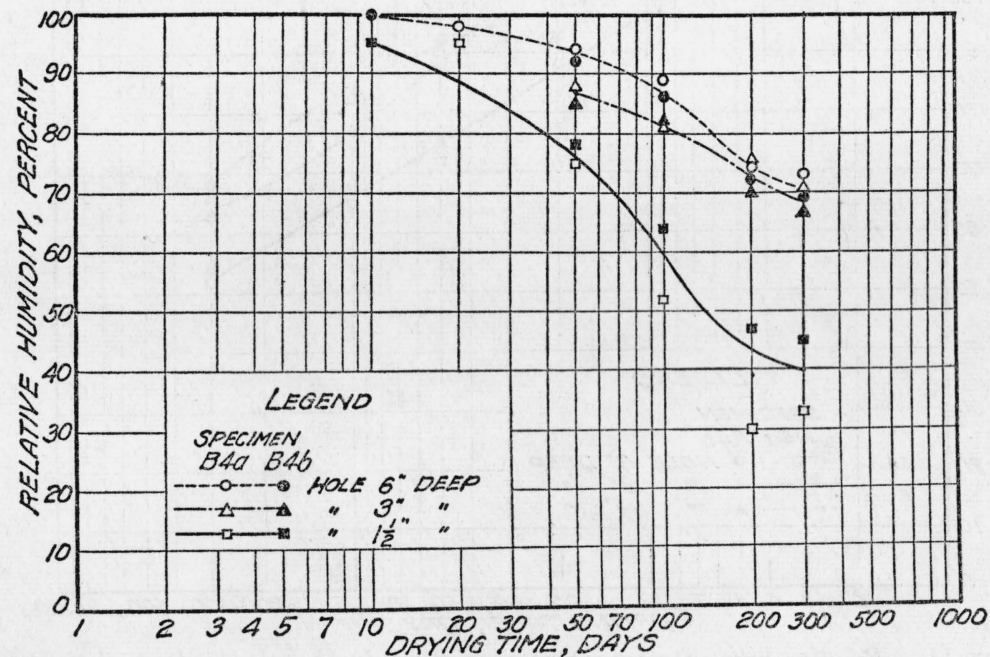

FIGURE 13.-Relative humidity in coated specimens damp-cured 4 days, then stored at 20-percent relative humidity, $100^{\circ} \mathrm{F}$ (pair B4).

In order to obtain specimens which were better sealed on all but one side, three (6-by 12-inch) concrete cylinders were cast in tin molds and kept in these molds for the duration of the test.

Each specimen was cast with a 1-inch-diameter hole in the top. These holes were $1 \frac{1}{2}$ inches deep in specimen 1,3 inches deep in specimen 2 , and 6 inches deep in specimen 3 . The 3 -inch and 6 -inch holes in 
these specimens were lined to within an inch of the bottom with brass tubing inserted at the time of molding. After 7 days, the tops of the molds were removed and the specimens stored in the $100^{\circ} \mathrm{F}, 50$-percent relative humidity room. Relative-humidity measurements on these specimens are presented in table 2.

TABLE 2.-Relaitive humidity inside 6- by 12-inch cylinders stored at 50-percent relative humidity, $100^{\circ} \mathrm{F}$

\begin{tabular}{|c|c|c|c|}
\hline \multirow{3}{*}{ Drying time } & \multicolumn{3}{|c|}{ Relative humidity } \\
\cline { 2 - 4 } & $11 / 2$-inch hole & 3-inch hole & 6-inch hole \\
\hline & & & \\
\hline Days & Percent & Percent & Percent \\
30 & 78 & 96 & 98 \\
100 & 60 & 89 & 91 \\
300 & 57 & 86 & 88 \\
& & & \\
\hline
\end{tabular}

The results show a wide spread between the humidity near the surface and the humidity near the center of the specimen, as would be expected if all water loss had to take place from the top of the specimen.

\section{RELATIVE HUMIDITY INSIDE HERMETICALLY SEALED SPECIMENS}

\section{(a) EFFECT OF TEMPERATURE}

In order to determine the effect of change in temperature upon the relative humidity inside concrete with a fixed water content, the tops of the three cylinders used in the above tests were covered with metal caps and the cylinders brought to temperatures of $70^{\circ}$ and $60^{\circ} \mathrm{F}$ and then back to $100^{\circ} \mathrm{F}$, and the relative humidity was measured at each temperature. The results are given in table 3.

\section{TABLE 3.-Relative humidity inside hermetically sealed concrete at different temperatures ${ }^{1}$}

\begin{tabular}{|c|c|c|c|}
\hline \multirow{3}{*}{ Temperature } & \multicolumn{3}{|c|}{ Relative humidity } \\
\cline { 2 - 4 } & 11/2-inch hole & 3-inch hole & 6-inch hole \\
\hline & & & \\
\hline & Percent & Percent & Percent \\
100 & 57 & 86 & 88 \\
70 & 52 & 78 & 87 \\
60 & 50 & 73 & 79 \\
100 & 58 & 83 & 88 \\
\hline
\end{tabular}

1 The above cycle was repeated after 2 weeks' time without any appreciable difference in results.

The results show that the relative humidity decreases as the temperature decreases and that the change is reversible. It is worthy of note that this relation between relative humidity and temperature is opposite to the relation that would hold if sorption phenomena were absent, that is, if concrete consisted of noncolloidal material containing large pores filled with air and water vapor (no liquid water). In this case, if the temperature were decreased, the relative humidity of the air in the large pores would increase until the dew point, or 100-percent relative humidity, was reached. On the other hand, when sorption is pronounced, as in colloidal structure or porous materials with large 
surface (small pores), the relative humidity may decrease as the temperature decreases. This phenomenon has been reported in the case of wools [7], and it is indirectly shown to hold for silica gel by the data of Patrick [8].

\section{(b) EFFECT OF SETTING AND HARDENING OF CEMENT PASTE}

A series of tests was made in which the electric hygrometer was used to measure the relative humidity over cement pastes as the pastes aged. In these tests approximately $500 \mathrm{~g}$ of freshly mixed cement paste was placed in an 8-ounce glass bottle and the bottle immediately sealed with a rubber stopper and polystyrene cement. The bottles were then stored at $70^{\circ} \mathrm{F}$ and the relative humidity in the bottle was measured at different ages, the rubber stopper being removed and replaced with another stopper to which an electric hygrometer was attached. Preliminary work was done to assure that the method of sealing the bottles was efficient and to determine the effect of opening the bottle at each measurement. Specimens sealed in bottles and stored in the moist cabinet gave results which agreed with those obtained on similarly sealed specimens stored in the laboratory, nor could any change in weight be detected in either set with an analytical balance. A specimen in a bottle which had a hygrometer sealed in it throughout the test gave results which checked with those obtained by the usual method, in which the bottle was opened for each measurement. The results given in table 4, therefore, represent values for specimens which neither gained nor lost water during aging.

TABLE 4.-Relative humidity over neat paste stored in hermetically sealed bottles

\begin{tabular}{|c|c|c|c|c|}
\hline \multirow{2}{*}{ Age (days) } & \multicolumn{4}{|c|}{$\begin{array}{l}\text { High-early-strength cement, plus the } \\
\text { following percentages of } \mathrm{H}_{2} \mathrm{O}- \\
\text { [Normal consistency, } 27 \% \text { of } \mathrm{H}_{2} \mathrm{O} \text { ] }\end{array}$} \\
\hline & $\begin{array}{c}23 \% \text { of } \\
\mathrm{H}_{2} \mathrm{O}\end{array}$ & $\begin{array}{c}24 \% \text { of } \\
\mathrm{H}_{2} \mathrm{O}\end{array}$ & $\begin{array}{c}25 \% \text { of } \\
\mathrm{H}_{2} \mathrm{O}\end{array}$ & $\begin{array}{c}27 \% \text { of } \\
\mathrm{H}_{2} \mathrm{O}\end{array}$ \\
\hline $\begin{array}{l}2 \\
4 \\
4 \\
5 \\
51 \\
37\end{array}$ & $\begin{array}{l}\% \\
87 \\
82 \\
(\mathrm{a}) \\
79 \\
78 \\
76 \\
(\mathrm{a}) \\
75\end{array}$ & $\begin{array}{l}\% \\
(\mathrm{a}) \\
(\mathrm{a}) \\
82 \\
80 \\
79 \\
(\mathrm{a}) \\
76 \\
(\mathrm{a})\end{array}$ & $\begin{array}{l}\% \\
88 \\
86 \\
84 \\
84 \\
82 \\
(\mathrm{a}) \\
(\mathrm{a}) \\
80\end{array}$ & $\begin{array}{l}\% \\
(a) \\
88 \\
86 \\
84 \\
82 \\
81 \\
(\mathrm{a}) \\
80\end{array}$ \\
\hline \multirow{2}{*}{$37-20$} & \multicolumn{4}{|c|}{$\begin{array}{l}\text { Moderate heat-of-hardening cement, plus } \\
\text { the following percentages of } \mathrm{H}_{2} \mathrm{O}- \\
\text { [Normal consistency, } 22 \% \text { of } \mathrm{H}_{2} \mathrm{O} \text { ] }\end{array}$} \\
\hline & $\begin{array}{c}17 \% \text { of } \\
\mathrm{H}_{2} \mathrm{O}\end{array}$ & $\begin{array}{c}22 \% \text { of } \\
\mathrm{H}_{2} \mathrm{O}\end{array}$ & $\begin{array}{c}27 \% \text { of } \\
\mathrm{H}_{2} \mathrm{O}\end{array}$ & $\begin{array}{c}32 \% \text { of } \\
\mathrm{H}_{2} \mathrm{O}\end{array}$ \\
\hline 15 & $\begin{array}{l}96 \\
92 \\
90 \\
90 \\
88 \\
87 \\
86\end{array}$ & $\begin{array}{l}(\mathrm{a}) \\
95 \\
94 \\
94 \\
94 \\
97 \\
88\end{array}$ & $\begin{array}{l}\text { (a) } \\
\text { (a) } \\
97 \\
97 \\
\text { (a) } \\
\text { (a) } \\
\text { (a) }\end{array}$ & $\begin{array}{r}(\mathrm{a}) \\
(\mathrm{a}) \\
(\mathrm{a}) \\
(\mathrm{a}) \\
(\mathrm{a}) \\
100 \\
97\end{array}$ \\
\hline
\end{tabular}

so determination made. 
These results show (1) the variation in relative humidity with time and with small changes in amount of mixing water, and (2) the difference in relative humidity over pastes made from two widely differing cements. An apparent relation between strength and reduction in relative humidity is indicated by the fact that the briquette strengith and the relative humidity for the high-early-strength cement aged 3 days were respectively the same as the strength and relative humidity for the moderate heat cement aged 28 days.

\section{ACCURACY OF METHOD}

The accuracy with which the relative humidity inside concrete can be determined with the electric hygrometer depends, to some extent, upon the care with which the calibration is checked at the time the relative humidity is measured. The first instruments which were used changed in calibration with time, and in order to obtain an accuracy of \pm 2 percent it was necessary to check the calibration at least once a week. With the latest type unit this is not necessary. However, in very precise work, such as the determination of the relative humidity over hermetically sealed cement pastes, the hygrometer, when not in use, may be kept in a bottle at a known relative humidity and corrections made for any change in calibration. Such corrections are seldom greater than 2 percent relative humidity and are practically constant over the entire range of the hygrometer, that is, a calibration curve, as shown in figure 2 , is shifted to the right or left without changing slope. It is therefore necessary to check the calibration at one point only. By this method an accuracy of $\pm 1-$ percent relative humidity may be obtained.

\section{SUMMARY AND CONCLUSIONS}

1. The importance of the relative humidity inside concrete is pointed out, and the bearing which it may have on certain physical properties is suggested.

2. The electric hygrometer developed at the National Bureau of Standards for radio-sonde use is described, and a method is given for using this hygrometer to measure the relative humidity inside cavities within concrete.

3. Measurements of the relative humidity inside 12 -inch concrete cubes were made over a period of 300 days. The relative humidities inside uncoated specimens was as follows:

\begin{tabular}{|c|c|c|c|}
\hline \multirow{2}{*}{ Drying time } & \multirow{2}{*}{$\begin{array}{l}\text { Relative humidity } \\
\text { of drying room }\end{array}$} & \multicolumn{2}{|c|}{ Relative humidity inside concrete } \\
\hline & & 11/2-inch hole & 6-inch hole \\
\hline $\begin{array}{r}\text { Days } \\
50 \\
300 \\
50 \\
300\end{array}$ & $\begin{array}{r}\text { Percent } \\
50 \\
50 \\
20 \\
20\end{array}$ & $\begin{aligned} & \text { Percent } \\
& 70 \\
& 50 \\
& 52 \\
& 20\end{aligned}$ & $\begin{array}{r}\text { Percent } \\
92 \\
66 \\
90 \\
60\end{array}$ \\
\hline
\end{tabular}

The relative humidity inside coated specimens was higher than in the uncoated specimens, but the results indicated that none of the coatings were impermeable to water. 
4. The relative humidity inside hermetically sealed concrete specimens was found to decrease as the temperature decreased and to return to its original value when the temperature was increased to its original value.

5 . The relative humidity over neat-cement pastes of approximately normal consistency and cured in hermetically sealed containers was measured. The relative humidity decreased to 94 percent at 7 days and to 88 percent at 28 days, over a moderate heat-ofhardening cement, and decreased to 88 percent at 3 days, to 82 percent at 7 days, and to 79 percent at 28 days, over a high-early-strength cement.

6 . The electric hygrometer appears to be well suited to the measurement of relative humidity inside concrete and over cement pastes.

The authors express their appreciation to F. W. Dunmore for supplying the necessary hygrometers and for his valuable suggestions as to their use.

\section{REFERENCES}

[1] R. W. Spenser, Proc. Am. Concrete Inst. 34, 45 (1938).

[2] R. E. Davis and G. E. Troxell, Proc. Am. Concrete Inst. 25, 210 (1929).

[3] L. Jesser, Zement 16, 741 (1927); 18, 158 (1929).

[4] R. K. Schofield, Trans. Third International Congr. Soil Sci. 2, (1935).

[5] F. W. Dunmore, J. Research NBS 20, 723 (1938) RP1102.

[6] F. W. Dunmore, J. Research NBS 23, 701 (1939) RP1265.

[7] J. W. McBain, The Sorption of Gases and Vapours by Solids (Routledge \& Sons, London).

[8] W. A. Patrick, P. B. Davis, and E. H. Barclay, Colloid Symposium Annual, y, 131, 1930. (Johns Hopkins, 1929.)

Washington, June 22, 1940. 